\title{
HARRY POTTER AND THE CHAMBER OF SECRETS E SUA TRADUÇÃO PARA O PORTUGUÊS BRASILEIRO: DESTAQUES NO TEXTO FONTE E NO TEXTO TRADUZIDO, A PARTIR DA ARTICULAÇÃO ENTRE A GRAMÁTICA SISTÊMICO-FUNCIONAL E A LINGUÍSTICA DE CORPUS*
}

\author{
Osilene Maria de Sá e Silva da Cruz ${ }^{1}$
}

\begin{abstract}
Resumo
Diferentes escolhas de autores e tradutores revelam impactos importantes nos significados que podem estar associados a convenções da própria língua (de origem ou de chegada) ou a escolhas do autor e do tradutor, levando-se em consideração os contextos situacional e cultural. Pensando nessas escolhas, este trabalho tem por objetivo mostrar a análise de um corpus bilíngue paralelo, constituído por dois romances: Harry Potter and the chamber of secrets (1999), escrito em inglês americano, e sua tradução Harry Potter e a câmara secreta (2000), em português brasileiro. A partir da abordagem teórico-metodológica da Gramática Sistêmico-Funcional (HALLIDAY, 1994), da Linguística de Corpus e dos Estudos de Tradução e das ferramentas do programa WordSmith Tools (SCOTT, 1997), são analisadas as escolhas da autora e da tradutora. As ferramentas Wordlist, Aligner e Concord do referido programa contribuíram para o levantamento de dados quantitativos e qualitativos, permitindo-se identificar a presença de padrões nos textos analisados, por exemplo, a presença de padrões linguísticos de cada língua e de aspectos culturais da língua de partida e da língua de chegada. Esses resultados corroboram a relevância de se articular campos teórico-metodológicos distintos com o intuito de mostrar sua articulação, possibilitando melhores resultados na pesquisa.
\end{abstract}

Palavras-chave: Estudos de Tradução; Gramática Sistêmico-Funcional; Linguística de Corpus; Programa WordSmith Tools.

\begin{abstract}
Authors' and translators' different choices reveal important impact on meanings that can be associated to language features (source or target language) or to the writer's own choices, considering the context of situation or culture. Considering these choices, this research aims at presenting the analysis of a parallel corpus, constituted by two novels: Harry Potter and the chamber of secrets (1999), written in American English, and its translation Harry Potter e a câmara secreta (2000), in Brazilian Portuguese. Based on Functional Systemic Grammar approach (HALLIDAY, 1994), Corpus Linguistics and Translation Studies and on the software WordSmith Tools (SCOTT, 1997), the choices of the author and the translator were analysed. The devices Wordlist, Aligner and Concord contributed to survey of quantitative and qualitative data present in the novels, allowing the identification of patterns in these texts, such as linguistic patterns in each text as well as cultural aspects from the source and the target language. The results confirm the relevance in articulating distinct theoretical and methodological areas of studies, aiming at showing this articulation and providing better results to research.
\end{abstract}

Key Words: Translation Studies; Systemic-Functional Grammar; Corpus Linguistics; WordSmith Tools software.

\footnotetext{
* Gostaríamos de agradecer à Capes (Coordenação de Aperfeiçoamento de Pessoal de Nível Superior) pelo financiamento dos anais da VII Escola Brasileira de Linguística Computacional e do XIII Encontro de Linguística de Corpus processo $\mathrm{n}^{\circ}$ 3472/2015-87.

${ }^{1}$ Graduada em Letras - Português/Inglês; Mestre em Estudos Linguísticos-Estudos de Tradução (UFMG), Doutora em Linguística Aplicada e Estudos da Linguagem (PUC SP). Desde 2014, atua como Professora Adjunta da Graduação e PósGraduação do Instituto Nacional de Educação de Surdos - INES. Áreas de interesse: ensino de Língua Portuguesa como L2 e elaboração de material didático, pesquisas envolvendo análise discursiva embasada na Linguística Sistêmico-Funcional e Avaliatividade, estudos pesquisas sobre educação de surdos. Estudos sobre Linguística de Corpus e Estudos de Tradução. Email: osilenecruz@bol.com.br.
} 


\section{Introdução}

Estudos sobre tradução ou processo tradutório são cada vez mais recorrentes e contribuem para a análise contrastiva de enunciados em textos de partida e de chegada e para a identificação de padrões nesses textos, cujas escolhas dos autores envolvidos (autor e tradutor) podem ser motivadas por aspectos linguísticos inerentes a cada língua ou por questões culturais. Na Linguística Aplicada, esses estudos proporcionam à comunidade acadêmica (docentes e pesquisadores) subsídios sobre o processo de tradução, por meio de programas que identificam recursos utilizados por tradutores durante o processo, e também análise discursivas sobre o produto, ou seja, análise das escolhas de um autor e de um tradutor.

Vale ressaltar a importância de instrumentos, como programas computacionais eficazes que possibilitam análise mais concreta dos dados. O programa WordSmtith Tools (SCOTT, 1997), utilizado nesta pesquisa, consiste em uma ferramenta primordial, uma vez que proporciona a identificação de determinadas ocorrências, em termos quantitativos, que podem ser refinadas e interpretadas com mais exatidão, à luz de uma teoria fundante. No caso do corpus em análise, a presença significativa dos processos verbais say e ask (1197) no romance de partida não apresenta quantitativo equivalente no texto de chegada (950).

Este trabalho, fruto de uma pesquisa mais ampla, mostra a possibilidade de articulação entre três áreas de estudo: Estudos de Tradução, Linguística de Corpus e Linguística SistêmicoFuncional, no intuito de refletir sobre as escolhas verbais de uma autora e de uma tradutora, associadas à função ideacional, mais especificamente aos processos no sistema da transitividade que introduzem projeções paratáticas, ou seja, discurso direto. Para isso, apresento a análise de um corpus paralelo constituído pelos romances Harry Potter and the chamber of secrets (TF), de autoria de Joanne K. Rowling ${ }^{2}$, e Harry Potter e a câmara secreta (TT), traduzido por Lia Wyler.

A motivação para a escolha do corpus justifica-se, primeiramente, pelo sucesso de vendas e consumo do livro no Brasil, pois a referida série é considerada um "best seller" mundial, sendo traduzida para o mundo todo, proporcionando trocas de informações culturais e linguísticas. Trata-se de um exemplo atual, que aponta para o papel da tradução como veículo de conhecimento, fonte de leitura e entretenimento para um público específico.

A escolha do foco desta análise, os verbos de elocução, deve-se à significativa presença de diálogos no romance e ao fato de haver poucas pesquisas comparadas, sobretudo no par linguístico inglês-português do Brasil, envolvendo verbos de elocução e os processos que os mesmos realizam no sistema da transitividade. As diferentes escolhas por parte da autora e da tradutora criam configurações distintas dos personagens dos romances, de interesse para as análises de originais e traduções sob a perspectiva discursiva.

A seguir, apresento o referencial teórico que fundamenta este estudo.

\footnotetext{
${ }^{2}$ A versão inicial do romance, publicada na Grã-Bretanha, sofreu algumas adaptações na versão para o inglês americano, publicada pela editora Scholastic, em 1999. Esta pesquisa tomou como base a versão americana, por ser essa a que serviu de versão para a tradução. Informação obtida através da editora Rocco, que publicou o romance no Brasil. A tradução foi publicada no Brasil em 2000.
} 


\section{Referencial teórico}

\subsection{Interfaces: Estudos de Tradução - Estudos de Corpora - Linguística Sistêmico-Funcional}

Apesar de a disciplina Estudos da Tradução ser relativamente nova no campo da Linguística, percebem-se, cada vez mais, inúmeros estudiosos empenhados em pesquisar tanto os processos tradutórios como os produtos. Além disso, verifica-se que a ênfase nas análises atuais caracteriza-se como descritiva e não mais prescritiva, como ocorria em décadas anteriores. Estudos de Baker (1992) e Kenny (2001), entre outros, podem ser citados como os interessados em descrever o produto e o processo da tradução, considerando ideologias, aspectos culturais e contextuais e não simplesmente aspectos relativos ao significado em si.

As abordagens baseadas na Linguística de Corpus constituem uma forma eficaz para identificação de padrões em textos de partida e de chegada, possibilitando reconhecer de forma objetiva as características desses textos. Os Estudos de Corpora consistem em uma perspectiva de interesse à presente pesquisa, uma vez que proporcionam dados quantitativos exatos e resultados amplamente acessíveis, conduzindo o pesquisador a conclusões confiáveis. Baker (1992) destaca a importância dos Estudos de Corpora para os Estudos da Tradução por oferecerem ao pesquisador a identificação de padrões em textos traduzidos, proporcionando ao estudioso a compreensão sobre o comportamento tradutório.

Vários estudiosos reconhecem a importância da Linguística de Corpus tanto como metodologia ou como aparato teórico. Berber Sardinha (2004, p. 36), por exemplo, aponta que a LC “não se resume a um conjunto de ferramentas". Bernardes Gonçalves (2008, p. 387), por sua vez, evidencia a Linguística de Corpus "como uma metodologia facilitadora do trabalho de pesquisadores e críticos literários", destacando, dessa forma, seu papel facilitador, o que é corroborado por Bowker e Pearson (2002), quando definem a Linguística de Corpus como uma metodologia ou abordagem empírica, baseada no estudo de exemplos reais da linguagem escrita e oral.

A articulação dos Estudos de Tradução com outras áreas mostra-se muito relevante. Vasconcellos (1997), ao citar pesquisadores que recorreram à Gramática Sistêmico-Funcional (GSF) como teoria fundante em suas análises, destaca Newmark (1988) porque considera a linguística hallideana muito útil como ferramenta para verificar os significados apresentados pelos autores e sua transposição no texto traduzido. O pesquisador enfatiza suas análises relativas à coesão, construções metafóricas e variação gramatical.

De acordo com Vasconcellos (1997), ao idealizar a GSF, Halliday já articulava essa área de estudo com os Estudos de Tradução, focalizando a gramática acima do estudo da palavra e enfatizando as escolhas na língua-alvo, considerando, sobremaneira, o significado contextual. A GSF, portanto, oportunizou aos estudiosos da tradução uma ferramenta apropriada para a análise do discurso. Assim, ela tem sido utilizada por pesquisadores de tradução, oferecendo explicações sobre as escolhas lexicais, podendo estabelecer conclusões sobre relações de poder, hegemonia e diferenças culturais, a partir da análise micro ou lexical dos significados. Sobre a transitividade, foco desta pesquisa, Vasconcellos (1998: 218) destaca que "Através do sistema da transitividade, falantes/escritores organizam as realidades cognitivas da experiência e codificam em linguagem seu retrato mental destas realidades. A forma como a transitividade expressa a função ideacional é através dos processos". 
Baker (1992) propõe que a abordagem sistêmico-funcional em análises sobre tradução auxilia a identificar formas de coesão (coesão lexical, referência, substituição, elipse, conjunção e padrões de colocações) e estruturas de tema e rema em textos traduzidos. Segundo a pesquisadora, as estruturas temáticas do texto fonte e do texto traduzido merecem atenção, porque mostram como os significados são reproduzidos e retextualizados na cultura de chegada, considerando as especificidades culturais.

Dourado, Gil \& Vasconcellos (1995) basearam suas pesquisas na Gramática Sistêmico-Funcional, com ênfase nas escolhas lexicogramaticais. Na análise da retextualização do conto A very short story, de Ernest Hemingway, e sua tradução para o português do Brasil, Um conto bem curto, os autores enfatizaram o estudo das três metafunções: Dourado (metafunção textual), Gil (metafunção ideacional) e Vasconcellos (metafunção interpessoal).

As pesquisas mencionadas mostram que as contribuições proporcionadas pela Linguística Sistêmico-Funcional são significativas e eficazes como arcabouço teórico e metodológico nas análises linguísticas do texto traduzido.

Através da sua gramática, Halliday (1994) propõe a hipótese metafuncional, em que o sistema linguístico humano adulto é constituído pelos estratos fonológico, léxico-gramatical e semântico. O estrato semântico aborda três componentes funcionais, que são as metafunções: ideacional (experiência de mundo, conhecimento, crença), interpessoal (interação social entre os participantes, sujeitos sociais, identidades, relações sociais entre categorias de sujeitos) e textual (ligação de partes de um texto num todo coerente e de textos a contextos situacionais). Vale destacar que estas metafunções não operam separadamente; estão articuladas coerentemente.

A função ideacional, que é o enfoque desta pesquisa, pode ser analisada sob dois aspectos: o aspecto experiencial, onde a língua é apresentada como um sistema modelador, construindo o fluxo de consciência através da transitividade, e o aspecto lógico, que proporciona os recursos para a configuração das relações lógicas na estruturação dos grupos ou complexos. A oração é apresentada como representação. A ênfase nas escolhas focaliza os processos, os participantes e as circunstâncias, podendo-se analisar as relações sintáticosemânticas, ou seja, o tipo de processo e respectivos participantes. No nível da oração, a análise é realizada através da transitividade.

A análise da transitividade torna possível identificar dados acerca da função ideacional, ou seja, como estão presentes questões sobre experiência de mundo, conhecimentos e crenças nos textos fonte e de chegada. A análise dos processos que a autora e a tradutora utilizam nos personagens é reveladora de diferentes representações dos mesmos. Para a presente pesquisa, foram focalizados os processos utilizados como verbos de elocução.

\subsection{Aspectos discursivos dos verbos de elocução}

\subsubsection{Collins Cobuild English Grammar}

Como subsídio teórico-metodológico para identificar e classificar os verbos de elocução presentes no corpus, duas fontes foram acessadas: a Gramática Sistêmico Funcional - GSF (HALLIDAY, 1994) e a Collins Cobuild English Grammar (1990). Outras fontes foram utilizadas para categorizar os verbos encontrados nos romances, como o dicionário Collins Cobuild English Dictionary for Advanced Learners (2001) e o livro Collins Cobuild English Guides 5: reporting (THOMPSON, 1996).

A gramática Collins Cobuild English Grammar (1990) trata do tema Discurso Direto e Indireto, por meio de uma classificação dos verbos de elocução, de interesse para a presente pesquisa, de acordo com sua função no discurso, como se pode ver a seguir. 
Quadro 1: classificação dos verbos

\begin{tabular}{|c|c|}
\hline Classificação dos verbos & Exemplos \\
\hline Neutros & $\begin{array}{l}\text { enunciam a fala do locutor, sem acrescentar nenhuma informação. São } \\
\text { representados por "say"/“dizer" e "ask"/"perguntar" }\end{array}$ \\
\hline Propósito da fala & 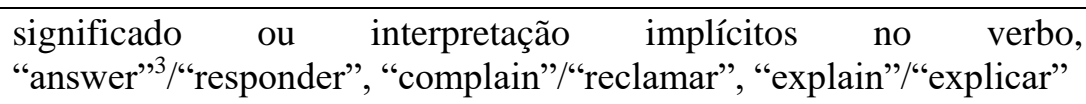 \\
\hline $\begin{array}{l}\text { Pensamento ou processos } \\
\text { mentais }\end{array}$ & $\begin{array}{lll}\text { "agree"//concordar", } & \text { "remember"/“lembrar", "think"/"pensar", } \\
\text { "wonder"/"imaginar" } & \end{array}$ \\
\hline Aprendizagem e percepção & "hear"/“escutar", "read"/“ler", "see"/“ver" \\
\hline Modo da fala & 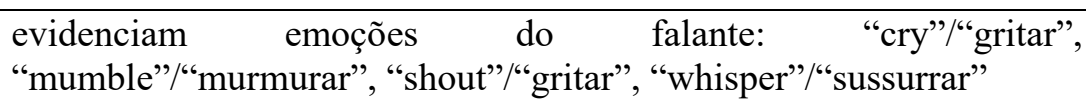 \\
\hline Sons particulares de animais & "bark"/“latir”, "snarl”/“rosnar”, "sniff”/“fungar” \\
\hline Expressão facial do falante & "smile"/“sorrir", "grin"/“sorrir mostrando os dentes". \\
\hline
\end{tabular}

Além da classificação acima, no presente trabalho, ficou evidente outra categoria, denominada verbos não intrinsicamente elocutórios. Como se trata de verbos frequentes no corpus e que introduzem ou concluem uma elocução, consideramos válida a sua classificação e inserção nesta análise. Tais verbos, como "clap on"/“bater nas costas", "try"/"tentar", "wave"/"acenar", apesar de não serem contemplados como elocutórios em nenhuma das fontes consultadas, exercem a função de verbos de elocução, transmitindo predominantemente uma expressão corporal e não verbal.

\subsection{Perspectiva Sistêmico-Funcional: processos e elementos circunstanciais}

Ao abordar o sistema de transitividade, Halliday (1994) apresenta os processos, um item gramatical pertencente à metafunção ideacional, que engloba os participantes de um evento, os processos e a circunstância. A transitividade verbal é representada por meio de seis tipos de processos: material, mental, relacional, comportamental, verbal e existencial, sintetizados a seguir.

Quadro 2: processos de transitividade e exemplos

\begin{tabular}{|l|l|}
\hline Processos & Exemplos \\
\hline Material & $\begin{array}{l}\text { evento ou ação relativos ao mundo exterior do indivíduo. Ex. } \\
\text { "make"/“fazer", "play"/“jogar", "tocar", "paint”/"cpintar" }\end{array}$ \\
\hline Mental & $\begin{array}{l}\text { sinaliza percepção, cognição e afeição. Ex. "see"/“ver", } \\
\text { "forget"/“esquecer", "like"/“gostar" }\end{array}$ \\
\hline Relacional & $\begin{array}{l}\text { constrói o ser de modos diferentes, variando entre o modo atributivo } \\
\text { (atributo ou qualidade) e o modo identificador (de identidade). Ex. "to } \\
\text { be"/"ser" }\end{array}$ \\
\hline
\end{tabular}

\footnotetext{
${ }^{3}$ Aparentemente, a Collins Cobuild English Grammar considera que "ask" é neutro, pois ele é utilizado para apresentar uma pergunta, a qual tem sinalização textual própria (o sinal de interrogação), independentemente do verbo que a introduz. Já "answer" apresenta um enunciado como tendo um propósito específico, qual seja, o de ser interpretado como resposta a uma pergunta.
} 


\begin{tabular}{|l|l|}
\hline Comportamental & $\begin{array}{l}\text { características mistas entre os processos mental e o material. } \\
\text { Representa comportamento tipicamente humano e trata-se de uma ação } \\
\text { praticada por participante consciente. Ex. "smell"/“cheirar", } \\
\text { "watch"/“assistir" "blink"/“piscar" }\end{array}$ \\
\hline Verbal $^{4}$ & $\begin{array}{l}\text { verbo típico de fala ("say"/“"dizer", "offer"/“oferecer") e introdutórios } \\
\text { de elocução. Ex.: "indicate"/“indicar", "show"/“mostrar" }\end{array}$ \\
\hline Existencial & $\begin{array}{l}\text { entre o processo relacional e o material, sendo as ações referentes ao } \\
\text { ser, existir e acontecer. }\end{array}$ \\
\hline
\end{tabular}

Fazendo uma analogia entre a classificação dos processos propostos na GSF e a dos verbos na Collins Cobuild English Grammar, pode-se perceber a possibilidade de articulação entre as duas propostas, uma vez que as categorias de verbos neutros, verbos sinalizadores do propósito da fala e do modo da fala podem ser associados aos processos verbais; verbos que sinalizam pensamento ou processos mentais podem ser associados aos processos mentais; assim como verbos que sinalizam aprendizagem e percepção e expressão facial do falante podem ser análogos aos processos comportamentais.

Halliday (1994) propõe a análise dos complementos verbais, denominando-os de "elementos circunstanciais". Tais elementos acompanham e atuam como expansão dos processos. Segundo o pesquisador, os elementos circunstanciais são expressos também por grupos adverbiais e sintagmas preposicionados.

O grupo dos sintagmas preposicionados possui duas funções na oração: adjunto ou qualificador de um grupo nominal. Na pesquisa em questão, mostraremos que os sintagmas preposicionados exercem função de adjunto adverbial de modo, ou seja, especificam o modo como alguns personagens proferem a fala, dando maior ênfase ao personagem do que ao processo propriamente dito.

Halliday (1994) subdivide os elementos circunstanciais em extensão, lugar, modo, causa, contingência, acompanhamento, função, importância e ponto de vista.

Destacamos aqui, a categoria modo (manner) porque é uma das mais utilizadas com os verbos de elocução no corpus desta pesquisa. Subdivide-se em meio, qualidade e comparação.

A subcategoria meio é responsável por transmitir o modo como o processo acontece e é expressa tipicamente por sintagma preposicionado como "with"/“com" ou "by"/“por".

Qualidade é o grupo adverbial tipicamente terminado em "-ly"/“-mente" e que qualifica o processo.

Comparação é frequentemente realizada através da preposição "like"/“como" ou "unlike"/"“diferentemente de" ou grupo adverbial de similaridade ou diferença.

\footnotetext{
${ }^{4}$ Neste artigo, estabelecemos a diferença entre os termos "verb process", traduzido como processo e "verbal process", traduzido como processo verbal, uma das categorias propostas por Halliday para os processos que introduzem uma elocução.
} 
Na presente pesquisa, foi possível encontrar na Gramática Sistêmica subsídios que explicam os complementos, chamados de elementos circunstanciais (advérbios terminados em "-ly"/“-mente" e sintagmas preposicionados), que ocorrem na língua inglesa. Na língua portuguesa, estes dois tipos de complementos são também utilizados, mas há, também uma terceira possibilidade, que é o adjetivo, raramente usado na língua inglesa, porém muito frequente no português brasileiro.

Perini (1996) desenvolve um estudo descritivo do português e propõe-se a usar terminologia diferente da gramática tradicional. Ele define o sintagma adjetivo como “... a classe dos constituintes que podem desempenhar a função de modificador interno ou modificador externo." (PERINI, 1996, p. 113). O autor usa o termo modificador para descrever adjetivos, como na seguinte oração: "Jeremias reclama indignado" (p.88), onde o sintagma indignado tem o papel de modificador de Jeremias, e dá a ele a diferente qualidade de estar indignado.

A abordagem de Perini revela-se adequada para a análise do presente corpus, uma vez que os adjetivos, encontrados no corpus, como complementos de verbos de elocução, modificam o falante. No exemplo, "Harry exclamou desesperado", temos o adjetivo desesperado como um sintagma desempenhando o papel de modificador do personagem Harry.

\section{Procedimentos da análise}

\subsection{Etapas da pesquisa}

Os arquivos foram digitalizados e formatados em "txt" para leitura eletrônica pelo software WordSmith Tools (Scott, 1997).

A ferramenta Word List mostrou o número total de palavras, confirmando a hipótese sobre a existência considerável de verbos de elocução e de diálogos.

Em seguida, as ferramentas Aligner e Concord possibilitaram a identificação e análise dos processos no TF e no TT, possibilitando visualizar as ocorrências dos processos concomitantemente nos dois textos (Aligner) e também visualizar a ocorrência de determinados processos de forma mais ampla e contextualizada no corpus (Concord).

As formas verbais encontradas foram contadas, categorizadas na forma de infinitivo do verbo, e classificadas, tendo como base as categorias propostas na Collins Cobuild English Grammar e a classificação dos processos pela GSF. Nesta etapa, foi criada outra categoria para os verbos de elocução: verbos não intrinsecamente elocutórios.

Após classificação e conferência dos verbos, iniciou-se a tabulação para o cálculo dos dados quantitativos e, posteriormente, a análise qualitativa. Nesta etapa, os dados foram tabulados e transferidos para tabelas ${ }^{5}$ separadas, para posterior análise qualitativa. Essas tabelas serviram para sintetizar os resultados e promover análise qualitativa dos padrões recorrentes no TF e no TT, assim como levantar hipóteses sobre as escolhas feitas pela autora e pela tradutora.

\footnotetext{
${ }^{5}$ Por uma questão de limitação de espaço, as tabelas não serão divulgadas. Maiores detalhes podem ser solicitados pelo e-mail osilenecruz@bol.com.br.
} 
Concomitantemente, foi realizado um levantamento sobre os complementos dos verbos (elementos circunstanciais): advérbio terminado em "-ly/-mente", adjetivo, sintagma preposicionado e verbo sem complemento ${ }^{6}$.

\subsection{Instrumento de análise: o Programa WordSmith Tools}

O WordSmith Tools foi desenvolvido por Mike Scott em 1996 e é comercializado pela Oxford University Press. Nesta pesquisa, utiliza-se a versão 3.0 (Scott, 1997). Segundo Berber Sardinha (2004), o programa dispõe de uma série de recursos úteis para a análise de ocorrências da linguagem. Dentre as ferramentas do programa, foram utilizadas a Lista de palavras, o Concordanciador e o Alinhador, sintetizados a seguir.

a) Word Lists/Listas de palavras - ferramenta que disponibiliza as listas de todas as palavras ou "tokens" do corpus (mais frequentes e menos frequentes,), em ordem alfabética ou em ordem de freqüência.

b) Aligner/ Alinhamento - apresentação dos textos em linhas alternadas - TF e TT.

c) Concord/ Concordanciador - ferramenta que oferece ao pesquisador uma lista de ocorrências de um item específico (BERBER SARDINHA, 2004), ou seja, visão dos elementos lexicais selecionados no corpus, possibilitando delimitação de ocorrências a direita e a esquerda desses itens, com uma visão ampla e contextualizada. Segundo Sinclair (2001), esta técnica é muito útil porque dá acesso a muitos padrões importantes na língua.

A seção a seguir mostra a análise dos dados e a discussão dos resultados.

\section{Análise e discussão dos dados}

\subsection{Dados gerais sobre os verbos de elocução e seus complementos}

O quadro abaixo mostra a síntese dos dados quantitativos do corpus, por ordem de frequência com o respectivo percentual.

\begin{tabular}{|l|l|l|l|l|}
\hline \multirow{2}{*}{ Tipos de verbos } & \multicolumn{2}{|l|}{ Texto fonte } & \multicolumn{2}{l|}{ Texto traduzido } \\
\cline { 2 - 6 } & $\begin{array}{l}\text { Ocorrência } \\
\mathrm{s}\end{array}$ & $\begin{array}{l}\text { Ocorrência } \\
\mathrm{s}\end{array}$ & $\%$ \\
\hline \hline Verbos neutros & 1197 & $70 \%$ & 950 & $57 \%$ \\
\hline Verbos que sinalizam o modo da fala & 246 & $14 \%$ & 306 & $18 \%$ \\
\hline Verbos que sinalizam o propósito da fala & 107 & $7 \%$ & 274 & $17 \%$ \\
\hline Verbos que sinalizam som particular de animal & 56 & $3 \%$ & 30 & $2 \%$ \\
\hline Verbos que sinalizam a expressão facial do falante & 51 & $3 \%$ & 37 & $2 \%$ \\
\hline Verbos não intrinsicamente elocutórios & 22 & $1 \%$ & 25 & $2 \%$ \\
\hline Verbos que sinalizam aprendizagem/percepção & 19 & $1 \%$ & 23 & $1 \%$ \\
\hline Verbos que sinalizam pensamento ou processos mentais & 15 & $1 \%$ & 22 & $1 \%$ \\
\hline TOTAL & 1713 & & 1667 & \\
\hline \hline
\end{tabular}

Quadro 3: total de verbos do corpus

\footnotetext{
${ }^{6}$ Algumas ocorrências como "de repente" e "alto" foram classificados como advérbios no texto traduzido, em analogia ao uso de advérbios correspondentes na língua fonte, "suddenly" e "aloud/loudly".
} 
O quadro 3 mostra algumas diferenças quantitativas relativas às escolhas da autora e da tradutora, onde se vê que o texto fonte (TF) apresenta 46 verbos a mais que o texto traduzido (TT), podendo ser um indicativo de omissões de verbos de elocução na tradução. Mostra também que o TF apresenta um número maior de verbos de elocução do que o TT nas categorias de verbos neutros, verbos que sinalizam som particular de animal e verbos que sinalizam a expressão facial do falante. O texto traduzido apresenta um número maior de verbos que sinalizam o modo da fala, o propósito da fala, aprendizagem/percepção, pensamentos ou processos mentais e verbos não intrinsicamente elocutórios do que o texto fonte.

$\mathrm{Na}$ distribuição dos verbos, a disparidade maior está nos verbos neutros, com um número de ocorrências maior no TF do que no TT em 247 verbos, sendo a maior parte das ocorrências o verbo "say". O texto traduzido apresenta um número consideravelmente maior de ocorrências dos verbos que sinalizam o propósito da fala. Enquanto no TF há 107 ocorrências, o TT apresenta 274, ou seja, 167 verbos a mais do que o TF. Esse dado revela que o verbo neutro "say" no TF é traduzido por outros de significado distinto, principalmente por verbos que sinalizam o propósito da fala.

Essa análise, realizada manual ou isoladamente, provavelmente não traria dados tão apurados e importantes para se verificar as escolhas da autora e da tradutora e de que modo essas escolhas podem interferir na intenção comunicativa do texto de partida. Por exemplo, ao escolher mais verbos que sinalizam som particular de animal (56) no TF, a autora demonstra sua intenção de mostrar os enunciados de forma mais agressiva, por meio de verbos sinalizadores de sons de animais, causando efeito para mostrar personagens com características animalescas.

No texto traduzido, por outro lado, as categorias predominantes (modo da fala, não elocutórios e de aprendizagem e percepção) mostram a intenção da tradutora em amenizar os processos tendo em vista que esses semanticamente sinalizam o modo como se fala, por meio de expressões que mostram o personagem como dotado de características de aprendizagem e percepção, portanto, pode ser um personagem mais cauteloso, mais consciente com relação ao modo como se fala e com o objetivo dessa fala.

O exemplo a seguir mostra o uso do processo verbal say traduzido pelo seu equivalente semântico. Harry coolly.

$<$ !--L1, S 165-->"Better not let your mum hear you talking about my school," said

<!--L2, S 165--> E melhor não deixar sua mãe ouvir você falando da minha escola disse Harry com toda a calma.

Com relação aos processos verbais "say" e "ask" no texto traduzido, observou-se que a tradutora utiliza o processo "perguntar", quando ocorre uma pergunta e não mantém o processo "dizer", como no texto de partida, sinalizando a explicitação de perguntas.

Nos exemplos abaixo, extraídos por meio da ferramenta Aligner/Alinhamento, podese verificar a escolha da tradutora pelo verbo "perguntar" para ocorrência de "say" no original.

$<$ !--L1, S 19-->"What's the matter?" said Harry.

$<$ !-L2, S 19-->- Que foi? - perguntou Harry. 
<!--L1, S 123-->"The right what?" said Harry nervously as the fire roared and whipped George out of sight, too.

<!--L2, S 123--> Na o quê certa? - perguntou Harry nervoso enquanto as chamas rugiam e arrebatavam Jorge de vista.

<!--L1, S 255-->" I'm a what?" said Harry.

$<$ !--L2, S 255--> Eu sou o quê? - perguntou Harry.

<!--L1, S 356-->"What do you want with him?" said Ernie in a quavering voice.

<!--L2, S 356--> Que é que você quer com ele? - perguntou Ernie com a voz trêmula.

<!--L1, S 378-->"All righ', Harry?" he said, pulling up the balaclava so he could speak.

<!--L2, S 378--> Tudo bem, Harry? - perguntou ele, empurrando o gorro para trás para poder falar.

Essa estratégia de traduzir o processo neutro por outro processo com sentido semântico mais específico mostra a intenção da tradutora em especificar a elocução, sem deixála neutra ou vazia de significado. Baker (1992) explica que fenômenos mais explicativos ocorrem na tradução e que esse dado faz parte da explicitação presente no texto traduzido, como uma das estratégias do tradutor em explicitar a mensagem ao leitor do texto de chegada. Vejamos os exemplos a seguir, em que a tradutora utiliza processos verbais diferentes do "say", utilizado no texto fonte.

<!--L1, S 303-->"I must ask you not to scream," said Lockhart in a low voice.

<!--L2, S 303--> Peço que não gritem - recomendou Lockhart em voz baixa.

<!--L1, S 85-->"I think we'd better go and wait by the car," said Harry.

$<$ !--L2, S 85--> Acho que é melhor irmos esperar ao lado do carro - sugeriu Harry.

$<$ !--L1, S 258-->"You could've fried an egg on your face" said Ron.

$<$ !--L2, S 258--> Você podia ter fritado um ovo na cara - comentou Rony.

Os exemplos ilustram a opção da tradutora em detalhar a proposta da elocução, pois os personagens não apenas dizem algo, mas, enfatizam sua elocução, ao recomendar, sugerir ou comentar algo. Assim, os personagens são configurados como seres, cuja voz é mais explícita, menos neutra.

O quadro 3 mostra a discrepância de ocorrências entre verbos que denotam sons particulares de animais nos dois textos, pois no texto fonte, verifica-se maior ocorrência e diversidade verbais deste tipo de processo do que no texto traduzido. No texto fonte, a autora utiliza 12 tipos diferentes desta categoria enquanto, no texto traduzido, a tradutora utiliza 07. $\mathrm{O}$ fato de o número de verbos no TF ser significativamente maior do que no TT pode indicar que a tradutora não tem o mesmo objetivo que a autora demonstra ter, de animalizar alguns personagens como o Hagrid. 
No texto traduzido, esse personagem é apresentado como uma pessoa com características físicas diferentes das características físicas grotescas apresentadas no texto fonte. Suas elocuções são amenizadas através de processos verbais que sinalizam o modo da fala ou o propósito da fala, enquanto no texto fonte, além de se expressar em um inglês, representado com características de oralidade muito particulares, as falas do personagem são representadas por verbos de elocução que sinalizam o som particular de animal. Os exemplos extraídos pelo Programa WordSmith ilustram esse dado.

$<$ !--L1, S 253-->"Not Azkaban?" croaked Hagrid.

<!--L2, S 253--> Não para Azkaban? - lamentou Hagrid, rouco.

<!--L1, S 284-->"An' how many did yeh have ter threaten "An' blackmail before they agreed, Malfoy, eh?" he roared.

<!--L2, S 284--> E quantos você precisou ameaçar e chantagear para concordarem hein, Malfoy? - vociferou.

$<$ !--L1, S 284-->"An' how many did yeh have ter threaten "An' blackmail before they agreed, Malfoy, eh?" he (Hagrid) roared.

<!--L2, S 284--> E quantos você precisou ameaçar e chantagear para concordarem hein, Malfoy? - (Hagrid) vociferou.

<!--L1, S 289-->"Yeh can' take Dumbledore!" yelled Hagrid, making Fang the boarhound cower and whimper in his basket.

<!--L2, S 289--> Você não pode afastar Dumbledore! - gritou Hagrid, fazendo Canino se agachar e choramingar no cesto de dormir.

$<$ !--L1, S 296-->"No!" growled Hagrid.

$<$ !--L2, S 296--> Não! - disse Hagrid com raiva.

Como se pode ver nos exemplos, no texto em português, Hagrid é apresentado como quem emite falas de forma mais suavizada do que no texto em inglês, inclusive a própria elocução evidencia uma pessoa com marcas de oralidade diferente no texto de partida ("An' how many did yeh have ter threaten "An' blackmail before they agreed, Malfoy, eh?") e no texto de chegada (E quantos você precisou ameaçar e chantagear para concordarem hein, Malfoy?). O leitor, dessa forma, obtém informações distintas sobre o personagem, evidenciando características físicas diferentes das características físicas grotescas apresentadas no texto fonte. Então, suas elocuções, diferentemente do texto fonte, são amenizadas através de processos que sinalizam o modo da fala ou o propósito da fala, enquanto no texto fonte, além de se expressar em um inglês, representado com características de oralidade muito particulares, nas falas do personagem, são utilizados mais processos que sinalizam o som particular de animal.

Em relação aos complementos dos verbos de elocução, que Halliday (1994) chama de elementos circunstanciais, observamos os seguintes dados.

Quadro 4: Total de complementos/ elementos circunstanciais

\begin{tabular}{|l|l|l|l|l|}
\hline Tipo de complemento & \multicolumn{2}{l|}{ Texto Fonte } & \multicolumn{2}{l|}{ Texto Traduzido } \\
\hline Sem complemento & 1229 & $71 \%$ & 1177 & $71 \%$ \\
\hline Advérbio & 403 & $24 \%$ & 130 & $8 \%$ \\
\hline
\end{tabular}




\begin{tabular}{|l|l|l|l|l|}
\hline Sintagma preposicionado & 68 & $4 \%$ & 156 & $9 \%$ \\
\hline Adjetivo & 11 & $1 \%$ & 199 & $12 \%$ \\
\hline TOTAL & 1711 & & 1662 & \\
\hline
\end{tabular}

Ao tratar do discurso direto e indireto, a gramática Collins Cobuild English Grammar (Biber et al., 1990) propõe que os advérbios e os sintagmas preposicionados, utilizados em discurso direto, podem oferecer mais informação para a fala. A referida gramática não fala em adjetivo como complemento do verbo de elocução, conforme prevê Perini (1996) sobre o uso dessa classe gramatical em discurso direto.

Nos romances analisados, observamos que os processos verbais, em sua maioria, não são seguidos de complementos (quadro 4), aqui categorizados como advérbios, adjetivos e sintagma. $\mathrm{O}$ índice de ausência de complemento nos romances é de $71 \%$ das ocorrências de processos verbais em projeções paratáticas. Esse dado confirma o proposto por Biber et al. (1999) na gramática Longman Grammar of Spoken and Written English, elaborada a partir de dados de corpora em formato eletrônico, de que textos de ficção predominantemente não apresentam expansões dos verbos de elocução. Seguem os exemplos.

$<$ !--L1, S 287--> Where is Miss Hermione Granger?

$<$ !--L2, S 287--> Onde está a Srta. Hermione Granger?

$<$ !--L1, S 230-->"We're friends of Hagrid's." Harry shouted.

<!--L2, S 230--> "Somos amigos de Hagrid" - gritou Harry.

Considerando o universo restante, ou seja, os $29 \%$ em que houve um desses complementos, a análise revelou que, das 482 expansões no TF e das 485 no TT, os advérbios (terminados em "-ly/mente") são mais frequentes no TF, com um total de 403 ou 84\% do total. No TT, por sua vez, correspondem a $27 \%$ do total, ou seja, acompanham 130 verbos de elocução. Podemos perceber que no texto fonte não há distribuição uniforme entre os complementos, porque a maioria dos complementos é constituída por advérbios $-84 \%$. No texto traduzido, por outro lado, houve distribuição entre os complementos, sendo $27 \%$ advérbios, $32 \%$ sintagmas preposicionados e $41 \%$ adjetivos.

Se compararmos TF com TT, podemos verificar que, no TF, o número de adjetivos como complemento é insignificante, com $2 \%$ das ocorrências, enquanto no TT, o percentual é de $41 \%$. É possível visualizar no quadro que no TF o uso de advérbio é de $84 \%$ e no TT este percentual cai para $27 \%$. Além de predominarem os adjetivos no texto traduzido, observamos também a preferência por sintagmas preposicionados, com $32 \%$ no texto traduzido, contra $14 \%$ no texto fonte, como nos mostram alguns exemplos.

$<$ !--L1, S 19-->"Nonsense, Petunia, I never went hungry when I was at Smeltings," said Uncle Vernon heartily.

<!--L2, S 19--> Bobagem, Petúnia, nunca passei fome quando estive em Smeltings disse tio Válter animado. 
<!--L1, S 23-->"You've forgotten the magic word," said Harry irritably.

<!--L2, S 23-->"Você esqueceu a palavra mágica" - disse Harry irritado.

Harry Potter.

<!--L1, S 201-->"Voldemort," said Riddle softly, "is my past, present, and future,

<!--L2, S 201--> Voldemort - disse Riddle com indulgência - é o meu passado, presente e futuro, Harry Potter.

Os exemplos indicam que, no TF, o uso dos elementos circunstanciais terminados em -ly reforçam o valor semântico do processo verbal. Então, ao "dizer algo animadamente", "irritadamente" ou "suavemente", ocorre destaque para os processos verbais "said". Em contrapartida, no TT, ao dizer algo "animado", "irritado" ou "com indulgência", o destaque do complemento recai sobre o personagem, denotando nele características pessoais. Sobre isso, Halliday (1994) informa que os elementos circunstanciais denotam caráter elucidativo para a fala dos personagens.

Um dado relevante encontrado no corpus desta pesquisa é a presença, embora reduzida, no TF, de adjetivo como elemento circunstancial. Apesar de o uso do adjetivo ser incomum na língua inglesa, que utiliza, predominantemente, advérbios terminados em "ly/mente", encontramos 11 casos em que o adjetivo aparece como complemento de verbos de elocução. Tal dado revela-se interessante, uma vez que não é contemplado pelas gramáticas em língua inglesa, por exemplo, a Collilns Cobuild English Grammar. O adjetivo como elemento circunstancial do verbo de elocução "say" aparece, 11 vezes, destacando o personagem e sua qualidade ou estado ao proferir a elocução, como ilustrado nos exemplos a seguir.

"You've got a new Seeker?" said Wood, distracted. "Where?"

"Oooh," said Colin, fascinated and raising his camera.

"Not kill you, sir, never kill you!" said Dobby, shocked.

"But that's very important!" said Hermione, shocked.

"For heaven's sake, Harry," said Hermione, exasperated...

"Azkaban?" said Harry, puzzled.

"He never wrote in it," said Harry, disappointed.

"What'll we do?" said Ron, aghast.

"Ginny!" said Mr Weasley, flabbergasted.

"Voldemort put a bit of himself in me?" Harry said, thunderstruck.

"No, I won't," said Hermione, suddenly severe. "You've had ten days to finish it"

Como dito nas linhas anteriores, esse tipo de complemento ou elementos circunstancial não é comum na língua fonte, onde se verificou maior presença de elementos que destacam a ação ou o processo e não o participante.

Seguem as considerações finais. 


\section{Considerações finais}

Este trabalho é um recorte de uma pesquisa mais ampla sobre o uso de verbos de elocução e dos processos da transitividade nos pares de textos em inglês e em português do Brasil. Mais especificamente, procurou-se investigar, através do estudo de corpora de pequenas dimensões, como se comportavam os verbos de elocução e de que forma poderiam influenciar no significado dos textos definitivos.

As análises realizadas pelas ferramentas do programa WordSmith Tools, especialmente, as listas de palavras, concordância e alinhamento, mostram a presença de diferentes "padrões" nos textos fonte e traduzido, evidenciando a configuração de personagens de forma distinta nos romances. Provavelmente, a simples leitura dos romances ou a comparação manualmente não evidenciariam aspectos da construção textual como foi possível fazê-lo neste estudo, por meio de software computacional eficiente (Programa WSTools) e sobremaneira pelas abordagens apresentadas na Gramática Sistêmico-Funcional e na Collins Cobuild English Grammar.

A análise revela a opção da tradutora por mesclar no texto de chegada a significativa frequência do verbo "say" no texto fonte. Para isso, utiliza outros verbos, entre eles o verbo "perguntar", numa tentativa de enfatizar a fala dos personagens. Além deste verbo, sua escolha revela a presença de verbos de outras categorias, como os verbos que sinalizam o propósito e o modo da fala e verbos que sinalizam aprendizagem e percepção. Pode-se especular que a intenção da tradutora, portanto, pode ser a de enfatizar a fala e não somente utilizar as falas de forma neutra.

$\mathrm{Na}$ tradução, os traços que tornariam os personagens dotados de características animalescas são amenizados. Isso pôde ser observado graças ao significativo índice inferior de verbos que sinalizam som particular de animal na tradução. Certamente, esse dado pode implicar diferenciação na interpretação por parte do leitor brasileiro que vai visualizar certos personagens como o Hagrid, por exemplo, como uma pessoa normal fisicamente, enquanto, no texto fonte, passa-se a nítida impressão de sua aparência grotesca, animalesca e rude. As elocuções do referido personagem também sofreram alterações na tradução, sendo apresentadas como as de um falante normal, enquanto, no texto de partida, as elocuções apresentam característica diferente.

Referindo-se à articulação entre as categorias dos verbos propostos pela Collins Cobuild English Grammar e os processos da transitividade da Gramática Sistêmico- Funcional, a análise possibilitou algumas disparidades entre os textos fonte e traduzido na análise dos personagens, que consistem no fato de que a autora optou por mais verbos que sinalizam o modo da fala e a tradutora por verbos que sinalizam o propósito da fala. Com relação aos processos, no texto fonte, temos os processos comportamentais e no texto traduzido os processos verbais.

O fato de a autora utilizar mais processos comportamentais e a autora os processos verbais pode ser uma evidência de que os personagens no texto de partida são mais conscientes de suas falas e ações. Por outro lado, o mesmo não ocorre com o texto traduzido, que apresenta os personagens como falantes, podendo ser conscientes ou não.

Através das escolhas da tradutora, fica clara a diferente explicitação de alguns personagens, sendo apresentados de forma mais enfática no texto de partida e assumindo verbos de elocução mais amenos na tradução. Esta estratégia da tradutora pode fazer com que o leitor do texto traduzido não perceba as mesmas configurações dos personagens apresentadas no texto de partida. 
Com relação aos elementos circunstanciais, ocorrem padrões distintos de cada língua: no texto de partida, os elementos mais frequentes são os advérbios de modo, com ênfase nos advérbios terminados em -ly/mente; no texto de chegada, o padrão vigente é a alternância entre o sintagma preposicionado e o adjetivo. Dessa forma, no texto fonte, a ênfase ocorre na ação e, no texto de chegada, consiste no falante.

É bem verdade que outras conclusões poderiam ter sido apresentadas neste estudo, as quais foram identificadas na análise como um todo, tendo em vista o rico corpus e o extenso levantamento de dados. Outros resultados, mesmo no âmbito da função ideacional da linguagem ou das metafunções interpessoal e textual, também poderiam mostrar os padrões de textualização no TF e de retextualização no TT. Esses e outros elementos excedem o escopo deste trabalho, que é um recorte de uma pesquisa mais ampla, na qual foi possível mostrar com mais riqueza de detalhes a configuração individual dos personagens analisados.

Apesar dessa limitação, tem-se a expectativa de que este trabalho possa auxiliar outros pesquisadores, novatos e experientes, no âmbito dos estudos discursivos, especialmente na LSF, no sentido de comprovar a realização de análise de línguas pares para obter resultados, associados à transitividade, à modalização, à estruturação e/ ou à organização de informações no texto, de forma a valorizar o estudo das metafunções ideacional, interpessoal e textual.

Por fim, cumpre destacar que a intenção desta pesquisa não é torná-la enfadonha, por outro lado, é uma tentativa de corroborar com os Estudos da Tradução, assim como com a Linguística de Corpora, no sentido de mostrar que a tradução sofre interferências do tradutor e de que sua invisibilidade não passa de mera especulação. Além disso, é uma forma de mostrar a eficácia das teorias aqui utilizadas para a explicação do fenômeno tradução.

\section{Referências}

BAKER, M. In other words: a coursebook on translation. London: Routledge, 1992.

Corpus Linguistics and Translation Studies: implications and applications. In: BAKER et al. (Ed.) Text and technology: In honor of John Sinclair. Amsterdam: John Benjamins Publishing Company, 1993. p. 233-250.

BERBER SARDINHA, T. Linguística de Corpus. São Paulo: Manole, 2004.

BERNARDES GONÇALVES, L. Linguística de Corpus e análise literária: o que revelam as palavras-chave. In: TAGNIN, S. Os avanços da Linguística no Brasil: pesquisa e crítica. São Paulo: Humanitas, 2008, p. 387-405.

BIBER, D. et al. Longman grammar of spoken and written English. London: Longman, 1999. p. 921-926.

BOWKER, L e PEARSON, J. Working with specialized language: a practical guide using corpora. London: Routledge, 2002.

HALLIDAY, M. K. A. An Introduction to functional grammar. $2^{\text {nd }}$ ed. London: Edward Arnold. 1994.

KENNY, D. Lexis and creativity in translation: a corpus-based study. Manchester: St Jerome Publishing. 2001. cap 2 e 3.

PERINI, M. Gramática descritiva do português. $2^{\mathrm{a}}$ ed. São Paulo: editora Ática, 1996. p. 8490 e $113-118$.

ROWLING, J. K. Harry Potter and the chamber of secrets. USA: Scholastic Inc, 1999. 
ROWLING, J. K. Harry Potter e a câmara secreta. Tradução de Lia Wyler. Rio de Janeiro: Rocco, 2000. (Título original: Harry Potter and the chamber of secrets).

SCOTT, M. WordSmith Tools. Versão 3.0. Oxford: Oxford University Press. 1997.

SINCLAIR, J. (Ed.) Collins Cobuild English dictionary for advanced learners. $3^{\text {rd }}$ ed. England: HarperCollins Publishers, 2001. 1824p.

VASCONCELLOS, M. L. Retextualizing Dubliners: a systemic functional approach to translation quality assessment. cap. 1 e 2. Tese (Doutorado em inglês/PGI) - Universidade Federal de Santa Catarina, Santa Catarina. 1997.

'Araby' and Meaning Production in the Source and Translated texts: a Systemic Functional View of Translation Quality Assessment. Cadernos de Tradução. Florianópolis: EDUFSC, vol. 3, p. 215-254. 1998. 